\title{
Primary health care registered nurses' types in implementation of health promotion practices
}

\author{
Virpi Maijala ${ }^{1}$, Kerttu Tossavainen ${ }^{2}$ and Hannele Turunen ${ }^{3}$ \\ ${ }^{1}$ PhD Student in Health Science, Department of Nursing Science, Faculty of Health Sciences, University of Eastern \\ Finland, Kuopio, Finland \\ ${ }^{2}$ Professor of Nursing, Department of Nursing Science, Faculty of Health Sciences, University of Eastern Finland, \\ Kuopio, Finland \\ ${ }^{3}$ Professor of Nursing, Head of the Department, Department of Nursing Science, Faculty of Health Sciences, University \\ of Eastern Finland, Kuopio, Finland
}

\begin{abstract}
Aim: This study aimed to identify and reach consensus among primary health care participants [registered nurses (RNs) who receive clients, directors of nursing, senior physicians, health promotion officers, and local councillors] on the types of service provider that RNs who receive clients represent in the implementation of health promotion practices in primary health care in Eastern Finland. Background: There is an increasing focus on public health thinking in many countries as the population ages. To meet the growing needs of the health promotion practices of populations, advance practice has been recognized as effective in the primary health care setting. The advance practice nurses share many common features, such as being RNs with additional education, possessing competencies to work independently, treating clients in both acute and primary care settings, and applying a variety of health promotion practices into nursing. Methods: The two-stage modified Delphi method was applied. In round one, semi-structured interviews were conducted among primary health care participants ( $n=42$ ) in 11 health centres in Eastern Finland. In round two, a questionnaire survey was conducted in the same health centres. The questionnaire was answered by $64 \%$ of those surveyed $(n=56)$. For data analysis, content analysis and descriptive statistics were used. Findings: This study resulted in four types of service provider that RNs who receive clients represented in the implementation of health promotion practices in the primary health care setting in Eastern Finland. First, the client-oriented health promoter demonstrated four dimensions, which reached consensus levels ranging between 82.1 and $89.3 \%$. Second, the developer of health promotion practices comprised four dimensions, which reached consensus levels between 71.4 and $85.7 \%$. Third, the member of multi-professional teams of health promotion practices representing three dimensions, with consensus levels between 69.6 and $82.1 \%$. Fourth, the type who showed interest towards health policy reached a consensus level of $55.4 \%$ in this study.
\end{abstract}

Key words: health promotion practice; primary health care; registered nurses

Received 26 August 2015; revised 25 October 2015; accepted 30 October 2015;

first published online 23 November 2015

Correspondence to: Virpi Maijala, PhD Student in Health Science, Department of Nursing Science, Faculty of Health Sciences, University of Eastern Finland, Canthia-building, Yliopistonranta 1C, P.O. Box 1627, FI-70211 Kuopio, Finland. Email: vkemppai@uef.fi

(C) Cambridge University Press 2015

\section{Introduction}

Health promotion has evolved towards the achievement of health equity, health as a human right, and political priority by taking actions based on the social determinants of health [World Health 
Organization (WHO), 2013]. This means that health and health promotion is defined largely by factors outside the health care sector and as part of public health thinking (Van den Broucke, 2013). Health promotion is defined as the process of enabling people to increase control over, and to improve, their health. It moves beyond a focus on individual behaviour towards a wide range of social and environmental interventions' (WHO, 2012). As public health has become a key issue for governments in many countries, for example in the European Union (EU), there has been concern about populations' health disparities related to life expectancy, which is strongly influenced by factors such as employment, income, level of education, and ethnicity. Therefore, the EU's health strategy 'Together for health' emphasizes promoting health, preventing diseases, and fostering supportive environments for healthy lifestyles, taking into account the 'health in all policies' principle (EU, 2014).

In Finland, the roots of public health promotion go back to the 1970s when the first public health law entered into force. Today, in accordance with the EU's health strategy, in Finland, the government guides and supports health promotion by means of legislation, action programmes, and recommendations (National Institute for Health and Welfare, 2013). The goal is to promote the welfare and health of the population in society as a whole. For example, health care legislation emphasizes the importance of maintaining and improving the health and quality of life of the whole population, preventing illnesses and health problems, as well as the reduction of health inequalities between population groups (The New Health Care Act, 2010).

According to the Constitution of Finland, public authorities must offer all citizens adequate social, medical, and health services and promote the health of the population. The Finnish social and welfare system is founded on governmentsubsidized services. Health care services are divided into primary health care and specialized medical care. Today, Finland has 160 primary health centres, which are operated by local authorities in municipalities. These health centres represent citizens' first point of contact with health care services and they are responsible for health promotion practices (HPPs) and preventive health care services such as health checks, screening, and follow-up (National Institute for Health and Welfare, 2013).

Despite long-term efforts to build up a public health policy, health promotion is especially challenging in Eastern Finland. This geographic area is rural, which is why distances to institutional health care can be very long. In addition, the population is ageing rapidly: $>20 \%$ of the population is older than 65 years, and unemployment and chronic conditions such as obesity and diabetes are more common than elsewhere in Finland (Organization for Economic Co-operation and Development, 2012). Therefore, advanced practice nurses have become a vital part of primary health care in Finland (Fagerström, 2009).

To meet the growing needs of HPPs of populations, the work of advanced practice nurses, such as nurse practitioners (NPs), has been recognized as effective in the primary health care setting (Burgess et al., 2011; Lowe et al., 2012; Donald et al., 2013). The NPs originated in the United States during the 1960s; since then, NPs have been introduced in a variety of settings in nursing worldwide (Sangster-Gormley et al., 2011). This development has led to a situation where NPs' educational requirements and scope of work vary greatly across countries (Delamaire and Lafortune, 2010). In addition, in most countries, there is a lack of consistency in legislative systems and regulatory mechanisms to recognize advanced nursing practices (Carney, 2015).

Nevertheless, similarities can also be found between the countries where NPs and advanced practice nurses have been introduced as follows: they are registered nurses (RNs) with additional education and training, who have professional autonomy, treat clients in acute and primary care settings, and apply a variety of health promotion activities such as disease prevention and health education and counselling into nursing (eg, Canadian Nurses Association, 2009; Royal College of Nursing, 2012; American Association of Nurse Practitioners, 2013; Nursing and Midwifery Board of Australia, 2013; Irish Practice Nurses Association, 2014). Internationally, Sastre-Fullana et al. (2014) have found advanced practice nurses to demonstrate competencies related to HPPs such as educating and teaching, evidence-based practice, consulting, advocacy, and communication. Advanced practice nurses, such as NPs, have been found to implement primary prevention, such as 
counselling on healthy nutrition, as well as secondary prevention, such as screening blood pressure (Berry, 2009). A recent study found primary health care NPs to deliver successfully lifestyle counselling aimed at overweight and obese clients (Jarl et al., 2014).

In the Finnish context, RNs who receive clients are authorized by the National Supervisory Authority for Welfare and Health (Valvira), have additional education, and work in primary health care centres share the same characteristics as advanced practice nurses in many countries. Their work is organized in such a way that they receive clients supported by doctor's consultation or in collaboration with a doctor (Delamaire and Lafortune, 2010). The scope of practice of these advanced practice nurses has been found to include tertiary preventive care and follow-up of clients with chronic conditions within many special areas such as cardiovascular diseases, diabetes, chronic pain, and mental health care (Fagerström, 2009). However, nurses are suggested to be active in primary prevention in the context of primary health care (Roden et al., 2015). Therefore, this study aimed to identify and reach consensus among primary health care participants (RNs who receive clients, directors of nursing, senior physicians, health promotion officers, and local councillors) on the types of service provider that RNs who receive clients represent in the implementation of HPPs in primary health care in Eastern Finland.

\section{Design}

\section{Delphi technique}

The Delphi technique is useful in situations when there is a lack of knowledge or agreement and when individual judgements need to be combined into group consensus (Powell, 2003). A two-stage modified Delphi technique was chosen as it allows the anonymous inclusion of a larger number of participants across diverse locations (Keeney et al., 2006). There is no commonly accepted standard for consensus (Hasson et al., 2000); however, researchers are recommended to define the level of consensus before commencement of the study (Keeney et al., 2006). A commonly accepted method for determining consensus is to set a percentage value for the level of agreement, which has ranged from 51 to $100 \%$ (McKenna, 1994; Williams and Webb, 1994). On the other hand, Keeney et al. (2006) suggested that $75 \%$ appears to be a minimal level, but there is no obvious scientific rationale for this. In this study, consensus was set at $51 \%$ (or over) 'completely agree' in the scale among the participants.

\section{Participants}

An invitation to this study was sent to all 34 primary health centres in three provinces in Eastern Finland. A total of 11 recipients responded and volunteered to participate in this study. They were from four health centres in Northern Carelia, four health centres in Northern Savo, and three health centres in Kainuu. There are no universally agreed criteria for participants in a Delphi study (Keeney et al., 2006). However, they should be familiar with the research topic and willing to contribute throughout the Delphi survey (Keeney et al., 2001). The participants in this study (RNs who receive clients, directors of nursing, senior physicians, health promotion officers, and local councillors) were required to have been employed for five years or longer in primary health care and they had to have experience of either working autonomously as an $\mathrm{RN}$ who receives clients or experience of working as part of a pair or team working with an $\mathrm{RN}$ who receives clients. In addition, they had to be interested in the research topic and willing to be involved throughout the Delphi survey. The possible 39 participants were suggested and named by directors of nursing at the primary health centres (matrons and head nurses). To ensure that local councillors, who were involved in municipal decision-making, were familiar with the research topic, one inclusion criterion was that they must have a nursing education background. There were three local councillors who met the inclusion criteria. The researcher asked potential participants for consent to be involved in the study; 42 agreed to participate $(100 \%$ response rate), including $18(43 \%)$ RNs (who receive clients), $14(33 \%)$ directors of nursing, four $(10 \%)$ senior physicians, three $(7 \%)$ health promotion officers, and three (7\%) local councillors. The demographics of the participants in round one are presented in Table 1. 
Table 1 Demographics of participants in Delphi rounds

\begin{tabular}{|c|c|}
\hline & $n(\%)$ \\
\hline \multicolumn{2}{|l|}{ Participants $(n=42)$ in round 1} \\
\hline Male & $3(7)$ \\
\hline Female & $39(93)$ \\
\hline RNs who receive the clients & $18(43)$ \\
\hline \multicolumn{2}{|l|}{ Educational background } \\
\hline RN and PHN & 5 \\
\hline RN and additional education in cardiovascular preventive care & 4 \\
\hline RN and additional education in diabetes preventive care & 3 \\
\hline RN and one year of studies for PHN & 2 \\
\hline RN, PHN, and additional education in diabetes preventive care & 2 \\
\hline RN, PHN, and additional education in diabetes and cardiovascular preventive care & 1 \\
\hline $\mathrm{RN}$ and additional education in wound care & 1 \\
\hline Directors of nursing & $14(33)$ \\
\hline \multicolumn{2}{|l|}{ Matrons } \\
\hline \multicolumn{2}{|l|}{ Educational background } \\
\hline $\mathrm{RN}$ and MNSc & 4 \\
\hline $\mathrm{RN}$ and postgraduate academic degree (PhD) & 2 \\
\hline \multicolumn{2}{|l|}{ Head nurses } \\
\hline \multicolumn{2}{|l|}{ Educational background } \\
\hline $\mathrm{RN}$ and MNSc & 5 \\
\hline RN and MNSc student & 2 \\
\hline RN, PHN, and Master's degree in health sciences & 1 \\
\hline Senior physicians & $4(10)$ \\
\hline \multicolumn{2}{|l|}{ Educational background } \\
\hline Medical doctor & 2 \\
\hline Licentiate of medicine & 2 \\
\hline Health promotion officers & $3(7)$ \\
\hline \multicolumn{2}{|l|}{ Educational background } \\
\hline MNSc & 2 \\
\hline Postgraduate academic degree (PhD) & 1 \\
\hline Local councillors & $3(7)$ \\
\hline \multicolumn{2}{|l|}{ Educational background } \\
\hline RN & 2 \\
\hline MNSc and senior lecturer of nursing & 1 \\
\hline \multicolumn{2}{|l|}{ Participants $(n=56)$ in round 2} \\
\hline Male & $6(11)$ \\
\hline Female & 50 (89) \\
\hline RN who receive the clients & $31(56)$ \\
\hline Directors of nursing & $14(25)$ \\
\hline Senior physicians & $5(9)$ \\
\hline Health promotion officers & $3(5)$ \\
\hline Local councillors & $3(5)$ \\
\hline
\end{tabular}

$\mathrm{RN}=$ registered nurse: Bachelor degree programme 3.5 years, 210 (ECTS), training is offered at Universities of Applied Sciences; PHN = public health nurse: Bachelor degree programme four years, based on RN 210 (ECTS) and additional public health nursing studies 30 (ECTS), training is offered at Universities of Applied Sciences; MNSc = Master of Nursing Science: Master's degree, 300 (ECTS), training is offered at Universities.

\section{Round one}

\section{Data collection}

In Delphi round one, the goal is to recognize issues related to the research topic (Powell, 2003). In this study, data collection started with semi-structured interviews with the primary health care professionals $(n=42)$ between April and July 2009. The semi-structured interview themes were based on literature and research on RNs' HPPs. Focussed questions were developed around the following themes: primary health care RNs' 
Table 2 Example for data analysis in round one

\begin{tabular}{|c|c|c|}
\hline Main category & Subcategory & Examples from interviews \\
\hline \multirow[t]{4}{*}{$\begin{array}{l}\text { A developer of health } \\
\text { promotion practices }\end{array}$} & $\begin{array}{l}\text { Evidence-based } \\
\text { practice }\end{array}$ & $\begin{array}{l}\text { '... information changes so quickly. We need to read and utilize current } \\
\text { research in health promotion practices' (RN 3) }\end{array}$ \\
\hline & Planning & $\begin{array}{l}\text { '... nurses are familiar with the health needs of their clients ... In our } \\
\text { health centre nurses develop their health promotion practices } \\
\text { regarding the health needs of the ageing population in our community } \\
\ldots \text { for example, distances are long in our municipality and therefore it is } \\
\text { important to develop electronic services' (DN 9) }\end{array}$ \\
\hline & Implementing & $\begin{array}{l}\text { 'Nurses should be aware of national health promotion strategies, for } \\
\text { example the Health } 2015 \text { programme and implement those strategies } \\
\text { into health promotion' (HPO 2) }\end{array}$ \\
\hline & Coordinating & $\begin{array}{l}\text { 'In our health centre, nurses arrange and coordinate different peer- } \\
\text { support groups, for example, peer-support groups for overweight } \\
\text { patients and tobacco cessation' (RN 9) }\end{array}$ \\
\hline
\end{tabular}

$\mathrm{RN}=$ registered nurse; $\mathrm{DN}=$ director of nursing; $\mathrm{HPO}=$ health promotion officer

independent and collaborative work, development of HPPs, and their political involvement in HPP. The interview themes were pre-tested with five primary health care RNs who were not involved in the study. The interviews were conducted in the participants' place of work, tape-recorded, and transcribed.

\section{Data analysis}

In round one, content analysis is used to identify the major themes in a Delphi study (Powell, 2003); this began by reading through all the transcribed interviews and identifying meaningful units such as common words, sentences, and phrases related to the interview themes (Graneheim and Lundman, 2004). Meaningful units were sorted into subcategories and main categories, which were consistent with the semi-structured interview themes. First, meaningful units that identified primary health care RNs working independently indicated three dimensions in the implementation of HPPs, and these were sorted into the following subcategories: providing health promotion actions independently, assessing the urgency of preventive care, and advocacy. A main category for this RN type of service provider was considered to indicate a client-orientated health promoter. Second, meaningful units that described primary health care RNs' collaboration, teamwork, or pair work demonstrated two dimensions in the implementation of HPP, and these were sorted into the following subcategories: collaboration with other health care professionals and involvement in networks. The main category for this $\mathrm{RN}$ type of service provider was considered to represent a member of a multi-professional teams of health promotion. Third, meaningful units that described primary health care RNs developing their work indicated four dimensions in the implementation of HPP, and these were sorted into the following subcategories: evidence-based practice, planning, implementing, and coordinating. The main category for this RN type of service provider was considered to demonstrate a main category of developer of HPPs. Finally, meaningful units that described a dimension of primary health care RNs having contacts with municipal decision-making were considered to represent a main category of a type with interest in health policy. It seemed that the interview themes were appropriate, and no other themes came up. An example of the data analysis is presented in Table 2 .

\section{Round 2}

\section{Data collection}

Based on qualitative findings a structured questionnaire was developed in round two. Statements were drawn up for each dimension (see Table 3) that primary health care RNs who receive clients represented in the implementation of HPP; the questionnaire included 12 statements, scored on a five-point Likert scale: 1 (completely agree), 2 (partially agree), 3 (partially disagree), 4 (strongly 
Table 3 Results of consensus levels on RN types of service provider and dimensions in implementation of health promotion practices in primary health care in round 2

RN types of service provider and dimensions in implementation of health promotion practices
Level of consensus $[n(\%)]$

(1)

(1)

$(2) \quad(3)^{\mathrm{a}}$

Client-orientated health promoter

Providing health promotion practices independently (eg, health checks for different client groups such as diabetics and clients with cardiovascular diseases)

Providing health education independently (eg, counselling about different health risks)

Assessing the urgency of preventive care (eg, ordering diagnostic tests)

Being advocates in health promotion (eg, encouraging self-care activities)

Developer of health promotion practices

Developing their own health promotion practices based on current research evidence

Planning a development of health promotion practices in their own unit (eg, the health needs of older people)

Implementing national health promotion strategies into practice

Coordinating health promotion practices in their own unit (eg, organizing activities of peer support groups)

Member of multi-professional teams of health promotion

To work in collaboration with doctors in health promotion practices

To be involved in networks of health promotion

To work in collaboration with other health care professionals of health promotion (eg, dietician)

A type who had interest towards health policy

Having contacts with municipal decision-making

$\begin{array}{lrr}50(89.3) & 6(10.7) & \\ & & \\ 49(87.5) & 7(12.5) & \\ & & \\ 49(87.5) & 6(10.7) & 1(1.8) \\ 46(82.1) & 9(16.1) & 1(1.8) \\ & & \\ 48(85.7) & 5(8.9) & 3(5.4) \\ & & \\ 46(82.1) & 10(17.9) & \\ & & \\ 41(73.2) & 14(25.0) & 1(1.8) \\ 40(71.4) & 16(28.6) & \\ & & \\ 46(82.1) & 9(16.1) & 1(1.8) \\ 44(78.6) & 10(17.9) & 2(3.6) \\ 39(69.6) & 16(28.6) & 1(1.8) \\ & & \\ 31(55.4) & 19(33.9) & 6(10.7)\end{array}$

$\mathrm{RN}=$ registered nurse

${ }^{a}$ Scale included 1 (completely agree), 2 (partially agree), 3 (partially disagree), 4 (strongly disagree), and 5 (neither agree nor disagree)

disagree), and 5 (neither agree nor disagree). To ensure content and face validity (McIlrath et al., 2010), the questionnaire was pre-tested with five primary health care RNs who were not involved in the research. Minor changes in wording were made on the basis of their feedback. The questionnaire was sent to a larger group of 87 individuals, including those who were involved in round one, and additionally, to directors of nursing, RNs (who receive clients), and senior physicians in the same 11 primary health care centres who had not participated in Delphi round one. The contact information of potential additional participants was found on the websites of the primary health care centres. In round two, the inclusion criteria for participants were that they were familiar with the research topic and had been employed in primary health care for five years or longer. The questionnaire included information regarding the requirements for respondents. Data were collected in January and March of 2011. After two follow-ups, round two had a response rate of $64 \%$; 56 participants returned the questionnaire including 31 (56\%) RNs (who receive clients), 14 (25\%) directors of nursing, five $(9 \%)$ senior physicians, three $(5 \%)$ health promotion officers, and three (5\%) local councillors. Table 1 presents demographics of the participants in Delphi round two.

\section{Data analysis}

In round two, the data were analysed with the SPSS $^{\circledR}$ (v19.0; IBM Corporation, Somers, NY, USA). Descriptive statistics were described as frequencies and percentages of 'completely agree' in the scale responses.

\section{Results}

This two-stage modified Delphi study identified and reached consensus on four types of service 
provider that RNs who receive clients represented in the implementation of HPP in primary health care in Eastern Finland. First, the client-orientated health promoter demonstrated four dimensions in the implementation of HPP: providing HPP independently (eg, providing health checks, screening, weight control, and follow-up for various client groups) reached a consensus level of $89.3 \%$ $(n=50)$. Providing health education independently (eg, counselling on health risks, smoking cessation, and providing health education related to healthy lifestyle to individuals and various client groups) as well as assessing the urgency of preventive care (eg, ordering diagnostic tests) reached consensus levels of $87.5 \%(n=49)$ among the participants. Being an advocate in health promotion (eg, encouraging clients and their families to commit to self-care activities) reached a consensus level of $82.1 \%(n=46)$ in this study.

Second, the developer of HPPs also possessed four dimensions in the implementation of HPP: developing HPPs based on current research evidence in their own unit reached consensus level of $85.7 \%(n=48)$. Planning HPPs regarding the health needs of the population in Eastern Finland (eg, health needs related to ageing) reached a consensus level of $82.1 \%(n=46)$ among the participants. Implementing national health promotion strategies into practice reached a consensus level of $73.2 \%(n=41)$ in this study. According to the results of this study, developers of HPPs also coordinated HPPs in their own units (eg, organized activities of peer support groups); this reached a consensus level of $71.4 \%$ $(n=40)$.

Third, the member of multi-professional teams of health promotion represented three dimensions in the implementation of HPP: working in collaboration with doctors in HPP reached a consensus level of $82.1 \%(n=46)$. Being involved in networks of health promotion reached a consensus level of $78.6 \%(n=44)$ among the participants. Collaboration with other health care professionals on health promotion (eg, dietician) reached a consensus level of $69.6 \% \quad(n=39)$ among the participants.

Finally, this study resulted in a fourth type that RNs who receive clients represented in the implementation of HPP: the type who showed interest towards health policy. Its only dimension, having contacts with municipal decision-making, reached a consensus level of $55.4 \%(n=31)$ in this study. Table 3 presents the summary of the results in round two.

\section{Limitations of the study}

Although the participants in this study represented diverse backgrounds, the results identified and consensus was reached on four types of service provider with 12 dimensions that RNs who receive clients demonstrated in the implementation of HPP in primary health care in Eastern Finland. However, Keeney et al. (2001) note that the results of a Delphi study should be regarded as any qualitative research results. Therefore, this study results should be generalized with caution. The sample size was small and data were collected six and four years ago from one geographical area and there was an 18-month time gap between the data collection rounds. However, the findings of this study are still relevant in the Finnish context. Today, primary health care is citizens' first point of contact with health care services, and RNs deliver preventive health care services such as health checks, screening, and follow-up as well as healthpromotive services such as health education and counselling (Teperi et al., 2009; National Institute for Health and Welfare, 2013). According to Keeney et al. (2001), a heterogeneous group of participants from diverse backgrounds and knowledge improves the content validity of Delphi study. Therefore, the participants of this study were representative of the large geographical area and had various backgrounds in primary health care. The response rate was $100 \%$ in round one and $64 \%$ in round two, and the high response among the participants increases the validity of our study (Keeney et al., 2006). In addition, a pilot survey for the semi-structured interview and the questionnaire improved the feasibility and reliability of the study results (McIlrath et al., 2010). The recommended minimal level of consensus level of $75 \%$ suggested by Keeney et al. (2006) was reached in 10 dimensions that RNs who receive clients demonstrated in the implementation of HPP in primary health care in Eastern Finland. Only two dimensions, 'working in collaboration with other health care professionals of health promotion' and 'having contacts with municipal decision-making', reached consensus levels below 
$75 \%$. To increase the trustworthiness of the study, the characteristics of participants in both Delphi rounds, data collection, analysis process, and results were carefully described, allowing the reader to consider the relevance of the findings (Graneheim and Lundman, 2004).

\section{Discussion}

The highest levels of consensus were reached on the type of service provider representing the client-orientated health promoter in the implementation of HPP in primary health care. The findings of this study indicated that RNs who receive clients implemented various HPP by educating and counselling diverse client groups in primary health care. Previously, nurses were seen in Finland as being needed for tertiary preventive care and the follow-up of patients with chronic conditions (Fagerström, 2009). However, the results of this study confirmed that nurses implement a variety of health educational activities in the primary health care context (Keleher and Parker, 2013; Roden et al., 2015).

This study resulted in consensus on the type of service provider that represented the developer of HPPs who implemented national health promotion strategies into practice in their own health centre, utilized current research results in practice, and coordinated health promotion activities in their own unit. We may consider this result as related to the increased requirements for evidence-based practice in HPPs. As pointed out by Juneau et al. (2011) and Melnyk et al. (2014), advanced practice nurses are expected to apply research evidence into HPPs with high-risk clients to improve and maintain their health. This study also showed that developers of HPPs plan healthpromoting activities. This included actions such as planning, pre-testing, and implementing new HPPs, for example, for older clients. In the future, instead of institutional services, it is important to develop health services such as online, electronic, or new forms of joint services provided as a collaborative effort by different health care professionals that can be offered to different clients groups on wheels (National Institute for Health and Welfare, 2013; Government Publications, 2015).

The type of service provider representing the member of multi-professional teams of health promotion reached high levels of consensus on the dimensions working in collaboration with a doctor in HPPs $(82.1 \%)$ and being involved in networks of health promotion $(78.6 \%)$. However, collaboration with other health care professionals involved in health promotion reached a clearly lower level of consensus (69.6\%) in this study. This finding may perhaps indicate that nurses and doctors work closely together, whereas other health care professionals involved in health promotion (eg, dieticians) were only consulted when required by the client's situation. Therefore, it is important to strengthen nurses' collaboration with other health professionals, as nurses who work with multi-disciplinary health professionals have been found to have a better understanding of health promotion and develop their health promotion knowledge and practices (Roden and Jarvis, 2012).

This study identified but reached a low consensus level $(55.4 \%)$ on a type of service provider who demonstrates an interest towards health policy by having contacts with municipal decision-making in primary health care. There has been much public debate on this issue, and research has substantiated that nurses do not demonstrate a clear and notable wider health policy and political role in formulating and implementing health promotion agendas (Whitehead, 2011).

In summary, the primary health care system in Finland is unique in that serves as citizens' first point of contact with health care services and its approach is to maintain and improve health as well as to prevent illnesses in the population (The New Health Care Act, 2010; National Institute for Health and Welfare, 2013; Government Publications, 2015). On the other hand, The EU Framework Programme for Research and Innovation (Horizon 2020, 2014) supports the premise that health promotion orientation should guide health care services.

In Finland, we have Bachelor's degrees programmes (210 ECTS) for RNs and paramedics. In addition, we have Bachelor-level double degree programmes (240 ECTS): first education as RN (210 ECTS), followed by 30 ECTS additional nursing studies, for public health nurses (PHNs) and midwives. Only these four nursing professions have registered titles that are authorized by the National Supervisory Authority for Welfare and Health (Valvira). PHNs, first educated as RNs, 
have traditionally delivered health-promotive activities in various nursing contexts such as school and student health care, child and maternity clinics, as well as occupational health care, by coordination of vaccinations and prevention of infection epidemics. RNs can receive clients supported by doctor's consultation or in collaboration with a doctor in primary health care centres. Previously, primary health care RNs have been found to deliver tertiary preventive care and follow-up of clients with chronic conditions within several special areas such as cardiovascular diseases, diabetes, chronic pain, and mental health care (Fagerström, 2009). Therefore, these study findings are valuable as they revealed that primary health care RNs who received clients supported by doctor's consultation or in collaboration with a doctor represented three types of service provider in the implementation of health-promotive care: (i) client-orientated health promoter who provides health-promotive activities such as health checks or counselling on health risks for different client groups; (ii) developer of HPPs who, for example, plans a development of HPPs in their own unit; (iii) member of multi-professional teams who, for example, is involved in networks of health promotion. In addition, this study indicated that primary health care RNs who receive clients also represented a type of service provider with an interest in political decision-making by having contacts with political decision-makers in their municipalities. Therefore, nursing directors should strengthen primary health care RNs' understanding of the mechanisms of how their HPPs are guided by health policy.

\section{Conclusion}

Although there is a lack of national guidelines for legislative and regulatory mechanisms for nurses' advanced practices in Finland, this two-stage modified Delphi study identified and clear consensus was reached on four primary health care $\mathrm{RN}$ types of service providers that represented advanced level of practice in health promotion in primary health care in Eastern Finland. The findings suggest that the scope of practice in health promotion of these RNs was that of a clientorientated health promoter who provided extensive health promotion actions for various customer groups. It appeared that developers of HPPs planned and developed HPPs based on current research, implementing national health promotion strategies as well as coordinating health promotion activities in their own units. As members of multi-professional teams of health promotion, RNs collaborated with doctors and other health care professionals in health promotion and were involved in health promotion networks. In addition, this study indicated that primary health care RNs demonstrated their interest towards political decision-making by having contacts with political decision-makers.

These findings can be utilized for the development of nurses' advanced roles and scope of practice in primary health care as well as when drawing up educational standards and guidelines for legislative and regulatory mechanisms for nurses' advanced practices across countries.

\section{Acknowledgements}

The authors gratefully thank the participants in this study. Researcher V. M. would like to acknowledge the support of the Department of Nursing Science at the University of Eastern Finland. Authors' Contributions: study design: V. M., K. T., and H. T.; data collection and analysis: V. M. with K. T. and H. T. supervising the data collection and analysis process. Manuscript preparation: V. M. with K. T. and $\mathrm{H}$. T. making critical revisions to the paper. K. T. and H. T. supervised the research process.

\section{Financial Support}

This study received a specific grant from The Finnish Foundation for Nurse Education and The Finnish Nurses Association.

\section{Conflicts of Interest}

None.

\section{Ethical Standards}

Approval for this study was obtained from the ethics committee of a university hospital (statement number 120/2008). In addition, one researcher provided information regarding the study both orally and in written form and asked the participants for their consent. 


\section{References}

American Association of Nurse Practitioners. 2013: Scope of practice for nurse practitioners. Retrieved 19 April 2015 from www.aanp.org

Berry, J.A. 2009: Nurse practitioners' use of clinical preventive services. Journal of the American Academy of Nurse Practitioners 21, 454-60.

Burgess, J., Martin, A. and Senner, W. 2011: A framework to assess nurse practitioner role integration in primary health care. Canadian Journal of Nursing Research 43, 22-40.

Canadian Nurses Association. 2009: Position statement, the nurse practitioner. Retrieved 20 April 2015 from https:// www.cna-aiic.ca/ /media/cna/page-content/pdf-en/ps_nurse_ practitioner_e.pdf?la=en

Carney, M. 2015: Regulation of advanced nurse practice: its existence and regulatory dimensions from international perspective. Journal of Nursing Management, first published online 7 January 2015, doi: 10.1111/jonm.12278

Delamaire, M. and Lafortune, G. 2010: Nurses in advanced roles: a description and evaluation of experiences in 12 developed countries. Paris, France: Organization for Economic Co-operation and Development. Retrieved 5 March 2015 from http://dx.doi.org/10.1787/5kmbrcfms5g7-en

Donald, F., Martin-Misener, R., Carter, N., Donald, E.E., Kaasalainen, S., Wickson-Griffits, A., Lloyd, M., AkhtarDanesh, N. and DiCento, A. 2013: A systematic review of effectiveness of advanced practice nurses in long-term care. Journal of Advanced Nursing 69, 2148-61.

European Union (EU). 2014: Together for health: a strategic approach for the EU 2008-2013. Retrieved 10 November 2014 from http://ec.europa.eu/health/index_en.htm

Fagerström, L. 2009: Developing the scope of practice and education for advanced practice nurses in Finland. International Nursing Review 56, 269-72.

Government Publications. 2015: Finland, a land of solutions. Strategic Programme of Prime Minister Juha Sipilä's Government, 29 May. Retrieved 19 August 2015 from http://valtioneuvosto.fi/documents/10184/1427398/Ratkaisujen+ Suomi_EN_YHDISTETTY_netti.pdf/8d2e1a66-e24a-40738303-ee3127fbfcac

Graneheim, U.H. and Lundman, B. 2004: Qualitative content analysis in nursing research: concepts, procedures and measures to achieve trustworthiness. Nurse Education Today $24,105-12$.

Hasson, F., Keeney, S. and McKenna, H. 2000: Research guidelines for the Delphi survey technique. Journal of Advanced Nursing 32, 1008-15.

Horizon 2020. 2014: The EU Framework Programme for Research and Innovation. Retrieved 19 August 2015 from http://ec.europa.eu/programmes/horizon2020/en/h2020-section/ health-demographic-change-and-wellbeing

Irish Practice Nurses Association. 2014: General information leaflet. Retrieved 23 April 2015 from http://www. irishpracticenurses.ie/

Primary Health Care Research \& Development 2016; 17: 453-463
Jarl, J., Tolentino, J.C., James, K., Clark, M.J. and Ryan, M. 2014: Supporting cardiovascular risk reduction in overweight and obese hypertensive patients through DASH diet and lifestyle education by primary care nurse practitioners. Journal of the American Association of Nurse Practitioners 26, 498-503.

Juneau, C.E., Jones, C.M., McQueen, D.V. and Potvin, L. 2011: Evidence-based health promotion: an emerging field. Global Health Promotion 18, 80-89.

Keeney, S., Hasson, F. and McKenna, H.P. 2001: A critical review of the Delphi technique as a research methodology for nursing. International Journal of Nursing Studies 38, 195-200.

Keeney, S., Hasson, F. and McKenna, H.P. 2006: Consulting the oracle: ten lessons from using Delphi technique in nursing research. Journal of Advanced Nursing 53, 205-12.

Keleher, H. and Parker, R. 2013: Health promotion by primary care nurses in Australian general practice. Collegian 20, 215-21.

Lowe, G., Plummer, V., O'Brien, A.P. and Boyd, L. 2012: Time to clarify - the value of advanced practice nursing roles in health care. Journal of Advanced Nursing 68, 677-85.

McIlrath, C., Keeney, S., McKenna, H. and McLaughlin, D. 2010: Benchmarks for effective primary care-based nursing services for adults with depression: a Delphi study. Journal of Advanced Nursing 66, 269-81.

McKenna, H.P. 1994: The Delphi technique: a worthwhile research approach for nursing? Journal of Advanced Nursing 19, 1221-25.

Melnyk, B.M., Gallagher-Ford, L. and Fineout-Overholt, E. 2014: The establishment of evidence-based practice competencies for practicing registered nurses and advanced practice nurses in real-world clinical settings: proficiencies to improve healthcare quality, reliability, patient outcomes, and costs. Worldviews on Evidence-Based Nursing 11, 5-15.

National Institute for Health and Welfare. 2013: Health care in Finland. National Institute for Health and Welfare, Helsinki, Finland. Retrieved 5 November 2014 from http:// www.urn.fi/URN:ISBN:978-952-00-3395-8

Nursing and Midwifery Boarding of Australia. 2013: Nurse practitioner standards of practice. Retrieved 19 April 2015 from http://www.nursingmidwiferyboard.gov.au/CodesGuidelines-Statements/Codes-Guidelines.aspx

Organization for Economic Co-operation and Development. 2012: Economic survey of Finland. Retrieved 10 August 2014 from http://www.oecd.org/document/8/0,3746,en_2649_ 33733_49514888_1_1_1_1,00.html

Powell, C. 2003: The Delphi technique: myths and realities. Journal of Advanced Nursing 41, 376-82.

Roden, J.E. and Jarvis, L. 2012: Evaluation of the health promotion activities of paediatric nurses: is the Ottawa Charter for Health Promotion a useful framework? Contemporary Nurse 41, 271-84.

Roden, J., Jarvis, L., Campbell-Crofts, S. and Whitehead, D. 2015: Australian rural, remote and urban community nurses' health promotion role and function. Health 
Promotion International, first published online 2 April 2015, doi: 10.1093/heapro/dav018

Royal College of Nursing. 2012: Advanced nurse practitioners. An RCN guide to advanced nurse practitioners and programme accreditation. Retrieved 19 April 2015 from https://www.rcn.org.uk/

Sangster-Gormley, E., Martin-Misener, R., Downe-Wamboldt, B. and Dicenso, A. 2011: Factors affecting nurse practitioners implementation in Canadian practice settings: an integrative review. Journal of Advanced Nursing 67, 1178-90.

Sastre-Fullana, P., De Pedro-Gomez, J.E., Bennasar-Veny, M., Serranto-Gallardo, P. and Morales-Asencio, J.M. 2014: Competency frameworks for advanced practice nursing: a literature review. International Nursing Review 61, 534-42.

Teperi, J., Porter, M.E., Vuorenkoski, L. and Baron, J.F. 2009: The Finnish health care system: a value-based perspective. Sitra Reports 82. Helsinki: Edita Prima Ltd.
The New Health Care Act 30.12.2010/1326. 2010: Retrieved 4 August 2014 from www.finlex.fi/fi/laki/kaannokset/.../ en20101326

Van den Broucke, S. 2013: Editorial. Implementing health in all policies post Helsinki 2013: why, what, who and how. Health Promotion International 28, 281-84.

Whitehead, D. 2011: Health promotion in nursing: a Derridean discourse analysis. Health Promotion International 26, 117-27.

Williams, P.L. and Webb, C. 1994: The Delphi technique: a methodological discussion. Journal of Advanced Nursing 19, 180-86.

World Health Organization (WHO). 2012: Health promotion. Retrieved 10 August 2015 from www.who.int/topics/ health_promotion/en

World Health Organization (WHO). 2013: Helsinki statement on health in all policies. Eight Global Conference on Health Promotion, 10-14 June 2013, Helsinki, Finland. 